\title{
Pay Equity Sensitivity and Person-Environment Fit
}

\author{
Dr Kamarul Zaman Ahmad \\ Senior Lecturer, Faculty of Business \& Accountancy, University of Malaya \\ Kuala Lumpur, Malaysia \\ E-mail: drkamphd@yahoo.com
}

\begin{abstract}
Most previous studies of Person-Environment fit have failed to use objective measures of the work environment that are independent of the person examined. This study aims to further develop and improve the operationalisation of Person-Environment fit by investigating objective fit and by marrying concepts from Equity Theory (Adams, 1965). Equity sensitivity was measured as a personality trait by the 16PF (Cattel et al 1987) and group size (obtained from company records) was the objective measure of the work environment. On the basis of data from 257 shop-floor workers in a factory in Wales, UK, results of hierarchical multiple regression generally indicated that the relationship between sensitivity and pay satisfaction are moderated by group size such that the relationship is positive in small groups and negative in large groups.
\end{abstract}

Keywords: P-E fit, Objective fit, Equity theory, Sensitivity, Group size, Pay satisfaction, Hierarchical multiple regression

\section{Introduction}

Parsons' (1909) seminal work appears to be the first to have stressed the importance of both person and environment variables in vocational choice. There is an abundance of research that examined the degree of fit between the person and the environment i.e., person-environment fit or P-E fit and how that is associated with satisfaction. Kristof, Zimmerman and Johnson (2005) have given one of the most up-to-date and comprehensive review of the previous studies on P-E fit. So have Piasentin and Chapman (2006) and Verquer, Beehr and Wagner (2003) when they conducted a meta-analytic review of 46 and 21 studies of P-E fit respectively. Yet, despite the illuminating articles by Kristof et al., (2005, 1996), other researchers (Wessel, Ryan and Oswald, 2008) appear somewhat confused especially when it comes to operationalising objective fit. True objective fit, is the fit when the measures of the environment are taken from a separate source and not from the respondent who is providing the information relating to the 'person' variable (Kristof et al., 2005, 1996). One example of a measure of the environment that can be obtained from company records is group size. Until today, there has not been a single P-E fit study that addressed this issue specifically. Moreover, most P-E fit research looked at various conceptualisations of personality or values when measuring the person. However, equity sensitivity, as a measure of the persons has previously been ignored in P-E fit literature.

The objective of this study is to examine the degree of objective fit between the person and the environment and how that is associated with satisfaction. More precisely, it examines the interaction between equity sensitivity (person) and group size (an objective measure of the work environment) and how that is associated with pay satisfaction (dependent variable). For instance, does the relationship between equity sensitivity and pay satisfaction vary with group sizes? This is the main research question that this study aims to answer.

\section{Literature Review}

\subsection{Person-Environment fit or P-E fit}

P-E fit was summarised by Edwards (1996: 292) as follows: "In essence, P-E fit embodies the premise that attitudes, behaviour and other individual level outcomes result not from the person or environment separately, but rather from the relationship between the two (Lewin, 1951; Murray, 1938; Pervin, 1989)." Kristof (2005, 1996), Piasentin and Chapman (2006) and Verquer, Beehr and Wagner (2003) have done a thorough literature review and as such, the bulk of it will not be reproduced here. Rather, what is discussed in this paper is the two main ways of conceptualising fit - direct and indirect. This eventually leads to the researcher's justification and recommendation that the environment should be measured objectively (in order to get a correspondingly objective measure of fit).

Kristof et al., $(2005,1996)$ indicated that some researchers have used direct measures of fit i.e., by asking people explicitly whether they believe a good fit exists. Posner, Kouzes and Schmidt (1985) used such a method. In their study, managers directly rated how compatible their values were with those of their organizations and how often 
they had to compromise personal principles to meet organizational expectations. This method is plagued by the consistency bias (i.e., "I think that I fit well, so I must be satisfied with my job") and is therefore not adopted in the current research. Due to this drawback, some researchers have relied on indirect measures to assess fit. According to Kristof (1996), indirect measures are more reliable because the respondent is asked to rate the individual separately from the environment without being asked to assess the degree of fit. This method (hereinafter called "the moderator approach") does not insist on commensurate measures. The person and the environment can be measured separately (as they should be), using entirely different instruments. The nature and ranges of the two scales can be entirely different. This does not require the respondent to assess fit either directly or indirectly. In fact, it makes it virtually impossible for the respondent to even attempt to assess fit. In this respect, the moderator approach is superior in that the consistency bias inherent in the direct measurement of fit approach can be totally eliminated.

Furthermore, it can be argued that the biggest advantage with this method is that objective measures of the environment can be used. Objective measures are measures that do not require any conceptual transformation on the part of the respondent. Hence, it is entirely independent of the person (respondent). Unfortunately, many studies that have used the moderator approach have failed to capitalise on this advantage. For example, in Lee, Ashford and Bobko (1990), control was measured perceptually by the respondent. In Barrick and Mount (1993), autonomy was measured perceptually. Edwards (1991) criticised direct measures primarily because they confound the constructs of the person and environment, thereby preventing the estimation of their independent effects. Yet, amazingly, he did just that (in Edwards, 1996) - environmental supplies and personal values (S-V) fit were measured by asking respondents how much of each task was involved in their job and how much of each task they preferred! This procedure was also employed in another research by Livingstone, Nelson and Barr (1997) who also conducted a study that employed a similar measure of S-V fit in their research.

Although Edwards (1991) pointed out that there is a real need for future research to use objective measures (of either the person or the environment), he has not done so himself and there appears to be none done by others reported even until today. Thus, there is a pressing need for a research to be conducted that uses a truly objective measure i.e., one which is obtained from a source other than the respondent.

\subsection{Group Size}

Group size, a measure that can be obtained from company records, is one aspect of the work environment that can be measured objectively. Social interactions in groups are frequently characterized by conflicts between personal and collective interests (De Cremer and Leonardelli, 2003). Thus, it is not surprising that research has shown that smaller groups establish and maintain higher levels of communication (Lowry, Roberts, Romano, Cheney and Hightower, 2006) whereas larger groups have reported lower satisfaction (Frank and Anderson, 1971; Shaw, 1981; Slater, 1958; Worthy, 1950). As group size increases, almost every group experiences some degradation in group communication process due to social loafing (Chidambaram and Tung, 2005; Liden, Wayne, Jaworski, and Bennett, 2009). Dissatisfaction with large groups is also reflected by greater absenteeism and personnel turnover (Shaw, 1981). However, small groups are not always better than larger groups. Aiken and Wong (2003) discovered that for idea generation, groups may not be effective until they reach a certain size. However, this apparent controversy over which size is better can be summed up by Worthy (1950) who stated that mere size is unquestionably one of the most important factors in determining the satisfaction of employees and dissatisfaction can have serious consequences for the company.

\subsection{Equity theory and the personality trait of sensitivity}

Equity theory (Adams, 1963, 1965) proposed that we are concerned with how much we get (outcomes) in proportion to how much we contribute (inputs). According to equity theory, we then compare this ratio with that of another individual to determine whether the situation is equitable. When things are inequitable and the ratios are unequal, we are less satisfied. Huseman, Hatfield and Miles (1987) were among the first to challenge its basic tenets in their theoretical paper - they questioned the notion that all individuals are equally sensitive to equity, as some are more tolerant and some are less tolerant of inequity.

Some similarities can be seen between the concept of equity sensitivity (as operationalised by Huseman et al., 1987) and the personality trait of sensitivity operationalised by Cattell, Eber and Tatsuoka (1992) as one of the sixteen primary personality traits). According to Cattell et al., (1992), people whose traits are high on sensitivity crave affection and attention, are also fussy, insecure, anxious, theatrical, easily affected and have been often associated with mental breakdown. Therefore, the extremely sensitive person (Huseman et al., 1987) craves for equity, and it does not matter whether the inputs are greater than the outputs or the other way round - both are undesirable to them. For instance, Irving and Montes (2009) found that exceeded expectations are not always associated with 
high levels of satisfaction. Accordingly, people whose traits are very high on sensitivity (Cattell et al., 1992) strongly favour equity and also cannot tolerate inequity in either direction, whereas people whose traits are low on sensitivity are more tolerant of inequity. The satisfaction or dissatisfaction that people have concerning equity or inequity can be directed towards their pay.

\subsection{Development of Hypothesis}

Thus, the main objective of this study is to determine whether the relationship between the personality trait of sensitivity and satisfaction is moderated by group size. It has also been explained in the literature review that, highly sensitive people are more dissatisfied with pay inequity than less sensitive people. Where all group members are paid the same regardless of individual performance, it would be reasonable to propose that pay in large groups tends to be inequitable, whereas pay in small groups tends to be more equitable. This is a proposition of course, which could be untrue. However, ensuring pay equity is certainly more difficult as the group gets larger, simply because there are more people to consider. Therefore, it would be reasonable to propose that in large groups highly sensitive people will be more dissatisfied with their pay than less sensitive ones. In small groups the relationship would be opposite because the match between pay and output would be better i.e., more equitable. Accordingly, the hypotheses are:

Null Hypothesis 1O: The association between sensitivity scores and pay satisfaction scores is not moderated by group size.

Alternative Hypothesis 1A: The association between sensitivity scores and pay satisfaction scores is moderated by group size such that the association is negative for large groups and positive for small groups.

\section{Research Methodology}

\subsection{Sample}

Data on two-hundred and fifty-seven shop-floor workers who worked in groups were collected from a light manufacturing assembly plant in Wales, UK. The entire population of the workers on the shop-floor was three hundred. So, this research is almost a census for the organization. One person refused to participate in the survey and two other resigned before the test could be completed. The majority of the sample was females - there were one hundred and eighty females $(70 \%)$ and seventy seven males $(30 \%)$. The average age of the sample was thirty five (see Table 1). Test administration took place over a period of three months in the factory. The collection of data on the employees in the sample took place in sessions at which, from three to fifteen employees were present. Subjects were asked to supply their names to identify their work groups. Every attempt was made to reduce the respondents' worries and anxieties about participating in the research and that this research was mainly for academic purposes. As this study was conducted in the UK no prior ethics approval was required. Nevertheless, anonymity of the respondents were preserved as promised and the rights of the individual respondents were not infringed.

The rationale for choosing to study only one organization was that most P-E fit studies examine differences between rather than within jobs and professions despite the fact that there may be very large differences between them (Furnham, Toop Lewis and Fisher, 1995). In the said article, one of the three reported studies explored P-E fit among two groups of specialist nurses (paediatrics and intensive therapy) (twenty-six and twenty-nine respectively) and one group of general medical nurses (twenty-five). Another reason why data was collected from only one organization was to reduce the variance due to factors which are not measured but must still be controlled (or at least be subjected to some attempt at control). Examples of such factors are differences in company policies, company size, industry sector and geographical location. Adkins Ravlin and Meglino (1996), in their research (which has some similarities with this research), also confined their study to one organization (one-hundred and ninety-one production workers). Thus, it will actually be counter-productive to collect the data from different organizations in this case. Bouchard (1983: 367) stated "Many field studies involve only one organization or subject. While the one case study is generally sterile scientifically.... it need not be. ... A well chosen single case may seriously threaten a traditionally accepted hypothesis."

\subsection{Measures}

Group size was measured by the number of workers in the work team as shown in the company records. Sensitivity was measured by 6 items in the 16 PF (Cattell et al., 1992) that measures Factor I (see Appendix 1). One such example is "I think what people say in poetry could be put exactly in plain prose." Scoring instructions are provided by Cattell et al., (1992). The 16 PF remains a popular questionnaire until today and still being used by many researchers (Forero, Pujol, Olivares and Pueyo, 2009; Wang and Xu 2008; Cousineau, Hall Mel, Rosik 
and Hall, 2007). Pay satisfaction was measured by numerical scales adapted from another P-E fit study (Meir, Hadas and Noyfeld, 1997), ranged from 1 to 20 (1 being lowest and 20 being the highest level of satisfaction).

\subsection{Procedure for defining small and large groups}

The procedure for defining group size is as follows: The entire sample was split into three equal groups according to group size i.e., small, medium and large. Subsequently, only the large groups were compared with the small groups, the two being at the extremes. The basis of dividing the groups as such was to adopt a compromise between two opposing recommendations. Roberts and Foti (1998) and Adkins, Ravlin and Meglino (1996) used median splits to divide their sample into two equal groups and then proceeded to compare one group with another. This method has the advantage of utilising the entire sample in the analyses. However, the disadvantage with this method is that it will inevitably include those respondents who are at the borderline i.e., just below or just above the mean of the variable under investigation. As such, it was felt that three groups rather than two should be formed and the analyses restricted to the comparison of the two extreme groups only. For instance, Barrick and Mount (1993) divided their entire sample according to $+1,0$ and -1 standard deviation. However, the outcome was that there were rather small sub-samples at both ends of the spectrum $(n=59$ at the +1 standard deviation above the mean and $n=49$ at the -1 standard deviation below the mean) with a high 'wastage' $(n=149)$ in the middle of the range. The end result was a compromise and the entire sample was divided into three equal groups. The SPSS commands of "summarise - frequencies - statistics - cut points for 3 equal groups" were used to determine the appropriate maximum values for small groups and minimum values for large groups. The result was that groups comprising between two and seven members are classified as small, between eight to fourteen are considered medium, and between fifteen and twenty are considered large.

\section{Results}

\subsection{Reliability}

Cronbach coefficient alpha reliability scores for sensitivity were 0.73 . Cronbach coefficient alpha reliability scores for pay satisfaction are unavailable since they are one-item measures. Descriptives statistics are given in Table 1. Correlation coefficients between the main variables are given in Table 2. Generally, sensitivity is not significantly correlated with group size, pay satisfaction satisfaction.

\section{Insert Table 1 here}

Insert Table 2 here

\subsection{Hierarchical Regression}

Hierarchical multiple regression were conducted to test the significance of the moderating effect of group size. More specifically, tests of hierarchical regression were used to determine the significance of the interaction term (sensitivity multiplied by the group size) on pay satisfaction. In its simplest form, a hierarchical (sometimes called sequential) analysis involves entering the IVs singly or cumulatively in a prespecified sequence. The $\mathrm{R}^{2}$ and partial coefficients are examined at each step. In hierarchical regression "the researcher determines the order in which IVs are entered into the equation," taking into account logical or theoretical considerations (Tabachnick and Fidell, 1996: 149). The IVs $(u$ and $v)$ can be entered in block 1 of the analyses using the command "Enter" in the SPSS program. The interaction term $(u \times v)$ can then be introduced into the equation in block two. The term "introduced" rather than "entered" is used because, in block two, the interaction term is accepted into the equation only if, together with the individual component variables, it explains a variance in the dependent variable significantly more $(\mathrm{p}<.05)$ than the individual component variables alone. If the interaction term can significantly $(\mathrm{p}<.05)$ improve the predictive power of the equation, then it will form part of the regression equation. If it fails to significantly improve the $\mathrm{R}^{2}$ (squared semi-partial correlation), then the SPSS programme will not include the interaction term from the regression equation. The command used in block 2 was "Stepwise". Results of hierarchical multiple regression analyses are given in Table 3.

During the hierarchical multiple regression tests, the interaction term (sensitivity multiplied by the group size) was successfully accepted into the regression equation after the individual components (sensitivity and group size) have been entered into the equation. The results showed suppport for H1A in so far as group size was a significant moderator of the sensitivity-satisfaction relationships. Full details of the values of $\mathrm{R}^{2}$ were set out in Table 3. For instance Table 3, Column 3 showed the $\mathrm{R}^{2}$ values when only the sensitivity variable and the group size were entered into the regression equation. Column 4 of the same table show the $\mathrm{R}^{2}$ values when the sensitivity variable and group size as well as the interaction term were all in the equation. Column 5 of the same table show the change in $R^{2}$ as a result of introducing the interaction term. 
Insert Table 4 here

Table 4 shows the values of $b$ and the correlation coefficients in three scenarios: all cases, large groups only and small groups only. Figures 1 shows the graphs for large groups, small groups and all cases, for pay.

Insert Figure 1 here

Thus, the results of this research showed support for the H1A in that the relationship between sensitivity and pay satisfaction, were moderated by group size in so far as the said relationships were negative in large groups and positive in small groups, as indicated by the values of $\mathrm{b}$ and as evident from Figure 1. However, only the correlation between sensitivity and pay satisfaction was significantly positive in small groups $(.273, \mathrm{p}<.01)$. Correlations between sensitivity and pay satisfaction in large groups were not significant.

\section{Conclusion}

The results of this study lends support to the P-E fit theory in that people who fit into their environment tend to be more satisfied than those who do not. Sensitive people fit in working environments where pay is equitable. Where all group members are paid the same regardless of individual performance, pay in large groups tends to be inequitable, whereas pay in small groups tends to be more equitable. This is because social loafing is more likely to occur in larger as opposed to smaller groups. Results seem to suggest that, people whose traits are high on sensitivity have a tendency to be less satisfied with their pay if they are made to work in large groups. Highly sensitive people are more satisfied with their pay if they work in small groups where the pay rates come much closer to matching the individual output.

The results of this study also support the criticisms of the equity theory in that not all people are equally affected by inequity (Huseman et al., 1985), although the conceptualisation of equity sensitivity in this study is different. Furthermore, no distinction was made regarding whether a person perceives himself/herself as over paid or underpaid. Notwithstanding that, results suggest that highly sensitive people are more dissatisfied by inequity in either direction (as in large groups) compared with less sensitive ones. Highly sensitive people are also more satisfied in an equitable situation (as in small groups) compared with less sensitive ones.

From the managerial perspective, results seem to suggest that sensitive people should be made to work in smaller groups, where they will be more satisfied with their pay and not in larger groups where they will be less satisfied. However, to be able to do so, management would have to find out which workers are more sensitive and which are less sensitive. This would necessitate personality tests to be conducted on all the workers, a decision which may or may not be popular with the management or the workers. From the person-environment perspective, managers have two choices. Change the person or change the environment. Managers could either select only those people whose traits are low on sensitivity, or they could limit the group sizes so as not to exceed ten in number. The second alternative seems simpler, and this action would probably reduce the occurrence of social loafing hence resulting in increased productivity of the average worker. In addition, management can make individual contributions more visible.

\section{Limitations}

Since this study is cross sectional, a conclusion cannot be drawn about the direction of causality in these findings. However, it is reasonable to hold that the interaction between sensitivity and group size was for the most part responsible for changes in satisfaction rather than the reverse as the view taken in this research is that personality traits are relatively stable over long periods of time. Another weakness is that the moderator analyses were conducted in a single company. However, this can be argued to be a strength as many variables such as, company policies, company size, industry sector and geographical location are controlled because the study was conducted in the same factory. Such variables, if uncontrolled, may have varying effects on the moderator, the independent and dependent variables. The findings of this study can easily benefit from replication studies conducted in other companies with the same characteristics. It is also important to stress here that group size per se may not moderate the relationships found in this study. Rather, it is the inherent differences in characteristics of large and small groups that may be the cause of the moderating effect. For instance, if pay is tied to individual performance and not to group performance, there may be no moderating effect of group size on the sensitivity-pay satisfaction relationship. It is important that future replication studies fully replicate all the different characteristics of large and small groups and of the company itself. In defence, it can be argued that the differences that exist between small and large groups as well as the characteristics of the company are by no means unique and it is possible to find the same in other companies.

\section{References}

Adams, J. S. (1963). Toward an understanding of inequity. Journal of Abnormal and Social Psychology, 67, 
422-436.

Adams, J. S. (1965). Inequity in social exchange. Advances in Experimental Social Psychology, 2, 267-299.

Adkins, C. L., Ravlin, E. C., \& Meglino, B. (1996). Value congruence between co-workers and it's relationship to work outcomes. Group and Organisation Management, 21(4), 439-460.

Aiken, M., \& Wong, Z. (2003). The effect of group size on electronic idea generation. International Journal of Human Resources Development and Management, 3(3), 265.

Barrick, M. R., \& Mount, M. K. (1993). Autonomy as a moderator of the relationships between the Big Five personality dimensions and job performance. Journal of Applied Psychology, 78(1), 111-118.

Bouchard T. J. JR. (1983). Field research methods: interviewing, questionnaires, participant observation, systematic observation, unobtrusive measures. In Dunnette, M. D. (Ed.), Handbook of Industrial and Organizational Psychology, John Wiley \& Sons.

Cattell, R. B., Eber, H. W., \& Tatsuoka, M. M. (1992). Handbook for the Sixteen Personality Questionnaire. Champaign Illinois: IPAT.

Chidambaram, L., \& Tung, L.L. (2005). Is out of sight, out of mind? An empirical study of social loafing in technology-supported groups. Information Systems Research, 16(2), 149-160.

Cousineau, A. E., Hall Mel, E. L., Rosik, C. H., \& Hall, T. W. (2007). The 16 PF and marital satisfaction inventory as predictors of missionary job success. Journal of Psychology and Theology, 35(4), 317-327.

De Cremer, D., \& Leonardelli, G. J. (2003). Cooperation in social dilemmas and the need to belong: The moderating effect of group size. Group Dynamics: Theory, Research, and Practice, 7(2), 168-174.

Edwards, J. R. (1991). Person-job fit: a conceptual integration, literature review and methodological critique. International Review of Industrial/ Organizational Psychology, 6, 283-357.

Edwards, J. R. (1996). An examination of competing versions of the person-environment fit approach to stress. Academy of Management Journal, 39(2), 292-339.

Forero, C. G., Pujol, D. G., Olivares, A. M., \& Pueyo, A. A. (2009). A longitudinal model for predicting performance of police officers using personality and behavioural data. Criminal Justice and Behavior, 36(6), 591-606.

Frank, F., \& Anderson, L. R. (1971). Effects of task and group size upon group productivity and member satisfaction. Sociometry, 34, 135-149.

Furnham, A., Toop, A., Lewis, C., \& Fisher, A. (1995). P-E fit and job satisfaction: a failure to support Holland's theory in three British samples. Personality and Individual Differences, 19, 677-690.

Huseman, R. C., Hatfield, J. D., \& Miles, E. W. (1987). A new perspective on equity theory: the equity sensitivity construct. Academy of Management Journal, 12(2), 222-234.

Irving, P. G., \& Montes, S. D. (2009). Met expectations: The effects of expected and delivered inducements on employee satisfaction. Journal of Occupational and Organizational Psychology, 82(2), 431-451

Kristof, A. (1996). Person-organisation fit: an integrative review of it's conceptualisations, measurement, and implications. Personnel Psychology, 49, 1-49.

Kristof, A., Zimmerman, R. D., \& Johnson, E. C. (2005). Consequences of individuals' fit at work: a meta-analysis of person-job, person-organization, person-group and person-supervisor fit. Personnel Psychology, 58, 281-342.

Lee, C., Ashford, S. J., \& Bobko, P. (1990). Interactive effects of "Type A" behavior and perceived control on worker performance, job satisfaction and somatic complaints. Academy of Management Journal, 33(4), 870-881.

Lewin, K. (1951). Field Theory in Social Science. New York: Harper.

Liden, R., Wayne, S.J., Jaworski, R.A., \& Bennett, N. (2004). Social loafing: a field investigation. Journal of Management, 30(2), 285.

Livingstone, L. P., Nelson, D. L., \& Barr, S. H. (1997). Person-environment fit and creativity: an examination of supply-value and demand-ability versions of fit. Journal of Management, 23(2), 119 - 146.

Lowry, P. B., Roberts, T. L., Romano N. C., Cheney, P. D., \& Hightower, R. T. (2006). The impact of group size and social presence on small group communication - does computer-mediated communication make a difference? Small Group Research, 37(6), 631-661. 
Meir, E. I., Hadas, C., \& Noyfeld, M. (1997). Person-environment fit in small army units. Journal of Career Assessment, 5, 21-29.

Murray, H. A. (1938). Explorations in Personality. Boston: Houghton Mifflin.

Parsons, F. (1909). Choosing a Vocation. Boston, MA: Houghton Mifflin.

Pervin, L. A. (1989). Persons, situations, interactions: the history and a discussion of theoretical models. Academy of Management Review, 14(3), 350-360.

Piasentin, K. A., \& Chapman, D. S. (2006). Subjective person-organisation fit: Bridging the gap between conceptualisation and measurement. Journal of Vocational Behaviour, 69, 202-221.

Posner, B. Z., Kouzes, J. M., \& Schmidt, W. H. (1985). Shared values make a difference - an empirical test of corporate culture. Human Resources Management, 24(3), 293-309.

Roberts, H. E., \& Foti, R. J. (1998). Evaluating the interaction between self-leadership and work structure in predicting job satisfaction. Journal of Business and Psychology, 12(3), 257-267.

Shaw, M. E. (1981). Group Dynamics. The Psychology of Small Group Behavior. New York: McGraw Hill.

Slater, P. E. (1958). Contrasting correlates of group size. Sociometry, 21, 129-139.

Tabachnick, B. G. \& Fidell, L. S. (1996). Using Multivariate Statistics. 3rd edn. New York: Harpur Collins College Publishers.

Verquer, M. L., Beehr, T. A., \& Wagner, S. H. (2003). A meta-analysis of relations between person-organization fit and work attitudes. Journal of Vocational Behaviour, 63, 473-489.

Wang, A. P., \& Xu, Y. (2008). Applicability of five-kind of personality inventory for college students' personality measurement: Comparison study with 16PF. International Journal of Psychology, 43(3), 480-480

Wessel, J. L., Ryan, A. M., \& Oswald, F. L. (2008). The relationship between objective and perceived fit with academic major, adaptability, and major-related outcomes. Journal of Vocational Behaviour, 72, 363-376.

Worthy, J. C. (1950). Organizational structure and employee morale. American Sociological Review, 15, 169-179.

\section{APPENDIX 1}

\section{Sensitivity Questionnaire}

1. I would rather exercise by

a) fencing and dancing

b) in between

c) wrestling and cricket

2. It would be more interesting to be

a) a bishop

b) uncertain

c) a colonel"

3. I enjoy routine constructive work using a piece of machinery or apparatus

a) yes

b) in between

c) no

4. I am more impressed by

a) acts of skill and grace

b) in between

c) acts of strength and power

5. If I could go back in time, I'd rather meet:

a) Columbus

b) Uncertain

c) Shakespeare

6. I think that what people say in poetry could be put just as exactly in plain prose 

a) Yes
b) Sometimes
c) No

Table 1. Descriptives

$\mathrm{N}=257$

\begin{tabular}{l|ll}
\hline & Means & Standard deviation \\
\hline Sensitivity & 5.54 & 1.92 \\
Pay satisfaction & 8.83 & 3.86 \\
Age & 35.57 & 10.66 \\
\hline
\end{tabular}

Table 2. Table of correlation coefficients

\begin{tabular}{l|ccc}
\hline & Sensitivity & Group Size & Satisfaction with pay \\
\hline Sensitivity & 1 & .775 & .232 \\
Group size & .018 & 1 & .372 \\
Satisfaction with pay & .075 & -.056 & 1 \\
\hline
\end{tabular}

$* * \mathrm{p}<.01, * \mathrm{p}<.05, \quad \mathrm{~N}=257$

Above diagonal $=$ significance

Below diagonal $=$ Pearson correlation coefficients

Table 3. Sensitivity and satisfaction moderated by group size

\begin{tabular}{l|l|l|l|l}
\hline Person Variable & Pay Satisfaction & \multicolumn{2}{|l}{ Hierarchical Multiple Regression } \\
\cline { 3 - 5 } & & $\begin{array}{l}\mathrm{R}^{2} \text { with P,E but excluding } \\
\text { interaction term }\end{array}$ & $\begin{array}{l}\mathrm{R}^{2} \text { including } \\
\text { interaction term }\end{array}$ & $\Delta \mathrm{R}^{2}$ \\
\hline Sensitivity & H1 & .009 & .038 & .029 \\
\hline
\end{tabular}

Table 4. Values of $\mathrm{b}$ and the correlation coefficients

\begin{tabular}{l|l|l|l|l}
\hline HYPOTHESIS & $\begin{array}{l}\text { STATISTICAL } \\
\text { ANALYSIS }\end{array}$ & $\begin{array}{l}\text { ALL } \\
\text { CASES } \\
(\mathrm{N}=257)\end{array}$ & $\begin{array}{l}\text { LARGE } \\
\text { GROUPS } \\
(\mathrm{N}=90)\end{array}$ & $\begin{array}{l}\text { SMALL } \\
\text { GROUPS } \\
(\mathrm{N}=97)\end{array}$ \\
\hline \begin{tabular}{l} 
H1 $\begin{array}{l}\text { Sensitivity \& pay } \\
\text { satisfaction }\end{array}$ \\
\cline { 2 - 5 }
\end{tabular} & Values of b & .149 & -.233 & .589 \\
\hline
\end{tabular}

$* * \mathrm{p}<.01, * \mathrm{p}<.05, \mathrm{~N}=257$ 


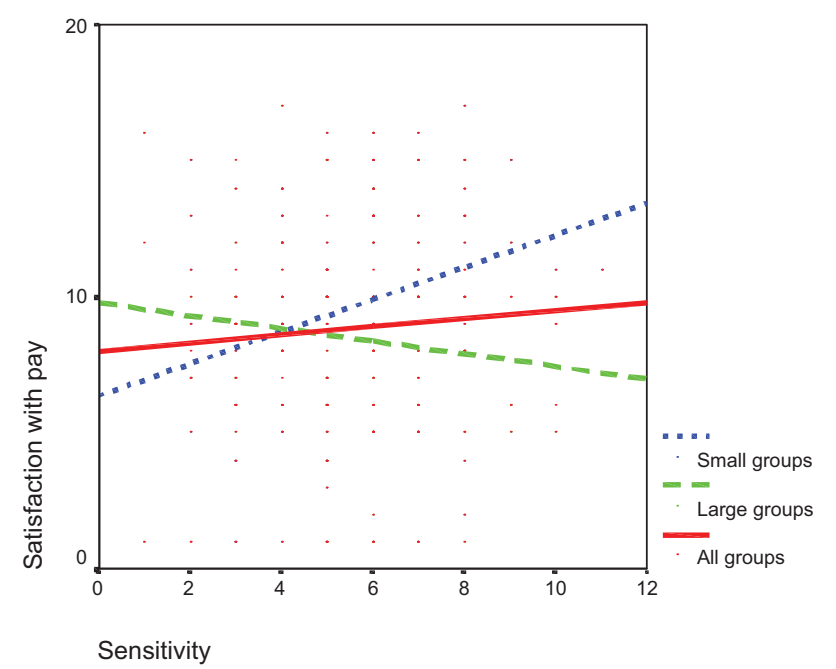

Figure 1. Interactional Effects of Group Size on the relationship between Sensitivity and Pay Satisfaction 